\title{
Analgesic effects of eucalyptus essential oil in mice
}

\author{
Ganggeun Lee', Junbum Park', Min Sun Kim², Geun Hee Seol ${ }^{3}$, and Sun Seek Min ${ }^{2}$ \\ ${ }^{1}$ Department of Anesthesiology and Pain Medicine, Eulji University Hospital, Daejeon, \\ ${ }^{2}$ Department of Physiology and Biophysics, Eulji University School of Medicine, Daejeon, \\ ${ }^{3}$ Department of Basic Nursing Science, Korea University School of Nursing, Seoul, Korea
}

Background: The use of aroma oils dates back to at least 3000 B.C., where it was applied to mummify corpses and treat the wounds of soldiers. Since the 1920s, the term "aromatherapy" has been used for fragrance therapy with essential oils. The purpose of this study was to determine whether the essential oil of Eucalyptus (EOE) affects pain pathways in various pain conditions and motor coordination.

Methods: Mice were subjected to inhalation or intraperitoneal injection of EOE, and its analgesic effects were assessed by conducting formalin, thermal plantar, and acetic acid tests; the effects of EOE on motor coordination were evaluated using a rotarod test. To determine the analgesic mechanism, 5'-guanidinonaltrindole ( -opioid antagonist, $0.3 \mathrm{mg} / \mathrm{kg}$ ), naltrindole ( $\delta$-opioid antagonist, $5 \mathrm{mg} / \mathrm{kg}$ ), glibenclamide ( $\delta$-opioid antagonist, $2 \mathrm{mg} / \mathrm{kg}$ ), and naloxone ( $\mu$-opioid antagonist, 4, 8, $12 \mathrm{mg} / \mathrm{kg}$ ) were injected intraperitoneally.

Results: EOE showed an analgesic effect against visceral pain caused by acetic acid (EOE, $45 \mathrm{mg} / \mathrm{kg}$ ); however, no analgesic effect was observed against thermal nociceptive pain. Moreover, it was demonstrated that EOE did not have an effect on motor coordination. In addition, an anti-inflammatory effect was observed during the formalin test.

Conclusions: EOE, which is associated with the $\mu$-opioid pain pathway, showed potential effects against somatic, inflammatory, and visceral pain and could be a potential therapeutic agent for pain. (Korean J Pain 2019; 32: 79-86)

Key Words: Acetic acid; Analgesics; Aromatherapy; Eucalyptus; Formaldehyde; Glyburide; Intraperitoneal injections; Mice; Naloxone; Naltrindole; Rotarod performance test; Opioid antagonists.

\section{INTRODUCTION}

Patients suffering from intense, chronic pain anticipate the development of new medicines that have little to no side effects; meanwhile, relying on numerous alternative medicines. Inhaling the fragrance of essential oils is considered to be an alternative medicine to achieve psychological and physical relaxation. Fragrances are used in cosmetics,

Received October 15, 2018. Revised January 18, 2019. Accepted January 21, 2019.

Correspondence to: Sun Seek Min

Department of Physiology and Biophysics, Eulji University School of Medicine, 77 Gyeryong-ro 771beon-gil, Jung-gu, Daejeon 34824, Korea Tel: +82-42-259-1633, Fax: +82-42-259-1639, E-mail: ssmin@eulji.ac.kr ORCID: https://orcid.org/0000-0001-7144-1987

(a) This is an open-access article distributed under the terms of the Creative Commons Attribution Non-Commercial License (http:// creativecommons.org/licenses/by-nc/4.0/), which permits unrestricted non-commercial use, distribution, and reproduction in any medium, provided the original work is properly cited.

(c) The Korean Pain Society, 2019 
foods, and in health-promoting agents. The utilization of fragrances dates back to at least 3000 B.C., where essential oils were used for mummification and in beauty products. There are even records of Hippocrates using fragrances to cure diseases. Scientific experiments have shown that when aromatic fragrances are inhaled, pain is sensed differently, unlike when unpleasant odors are inhaled [1].

Eucalyptus has been used in Brazilian traditional medicine as an anti-inflammatory, analgesic, and antipyretic agent, and to treat flu, common cold, and nose bleeds [2-4]. Modern science has also demonstrated such beneficial effects of Eucalyptus. However, further studies are necessary to confirm the precise pathways involved in the analgesic effects of Eucalyptus.

In this study, two methods were used to observe the analgesic effects of Eucalyptus in various pain models of mice: 1) inhalation of the essential oil of Eucalyptus (EOE) and 2) intraperitoneal injections for systemic administration. Pain models included formalin-induced, acetic acidinduced writhing, and thermal-stimulated pain. Behavioral experiments utilizing antagonists of pain-killers have been used to investigate which pain pathway is related to such analgesic effects. Moreover, drowsiness and dizziness may appear as side-effects after a medicine is injected. Certainly, side-effects need to be reduced for the medicine to be used clinically. Therefore, in this study, the rotarod test was used to investigate potential side effects caused by the drug.

\section{MATERIALS AND METHODS}

\section{Experimental animals}

Prior to the experiment, male C57BL/6 mice aged 8 weeks (Samtaco Inc., Osan, Korea) were maintained under a $12 \mathrm{~h}$ light-dark cycle (lights on from $7 \mathrm{AM}$ to $7 \mathrm{PM}$ ) at $21 \pm$ $2^{\circ} \mathrm{C}$. The animals had access to sterilized food and tap water as they desired and were subjected to the following tests: the formalin test, acetic acid test, rotarod test, and plantar test. Animals were used independently for each experiment. The guidelines of the Institutional Animal $\mathrm{Re}^{-}$ search Ethics Committee of Korea University (approval no. KUIACUC-2011-84) were followed for the care of the experimental animals in all experimental measures.

\section{Injection of $\mathrm{EOE}$}

Animals were injected with EOE (Aromarant Co. Ltd, Rottingen, Germany) dissolved in almond oil at 11.25, 22.5, 45,90 , and $180 \mathrm{mg} / \mathrm{kg}$ intraperitoneally in an injection volume of $0.1 \mathrm{ml} / 100 \mathrm{~g}$ body weight. Normal saline $(0.9 \%$ $\mathrm{w} / \mathrm{v}$ ) was administered to the control group, whereas almond oil alone was injected to the vehicle group. The control, vehicle, and essential oil groups were injected $30 \mathrm{~min}$ before the formalin, thermal plantar, and rotarod tests, and $35 \mathrm{~min}$ before the acetic acid-induced writhing test.

\section{Inhalation of EOE}

The hold-board apparatus consisted of a square transparent plexiglas cage $(50 \mathrm{~cm} \times 50 \mathrm{~cm} \times 30 \mathrm{~cm})$ with 4 holes in the bottom which were prepared for inhalation of the essential oils. The EOE was first combined with the same volume of distilled water and then absorbed in cotton that was set on the upper side of the inhalation box to ensure vaporization. A $1 \mathrm{ml}$ aliquot of EOE was vaporized in a petri dish $(90 \times 15 \mathrm{~mm})$ in the EOE group, while only distilled water was given to the control group. Before the formalin test, mice were exposed to the translucent Plexiglas cage for 1, 2, 4, and $8 \mathrm{~h}$, except for the group exposed to EOE.

\section{Drugs}

All drugs and vehicles were injected intraperitoneally 15 min prior to the EOE injection, except in the case of the inhalation tests, at a rate of $0.1 \mathrm{ml} / 100 \mathrm{~g}$ of body weight and included morphine $(4,8 \mathrm{mg} / \mathrm{kg})$, indomethacin (10 $\mathrm{mg} / \mathrm{kg})$, naloxone $(8 \mathrm{mg} / \mathrm{kg}), 5$ '-guanidinonaltrindole $(0.3$ $\mathrm{mg} / \mathrm{kg}$ ), and glibenclamide (2 $\mathrm{mg} / \mathrm{kg})$.

\section{Formalin test}

The formalin test was similar to the one reported by Hunskaar and Hole [5]. Twenty $\mu \mathrm{l}$ of formalin (2\% v/v) was injected into the mice $(n=7-12)$ dorsal surface of the left hind paw of the mice. The mice licking their injected paw were instantly timed. Their response was considered, based on the following: 1) 0-5 min after the formalin injection was the nociceptive pain response and 2) 20-25 min after was the inflammatory pain response. 


\section{Acetic acid-induced abdominal writhing test}

In accordance to Quintans-Júnior et al. [6], abdominal writhing was assessed in mice $(n=8-10)$. Acetic acid was injected intraperitoneally as a $0.5 \%$ solution $(10 \mathrm{ml} / \mathrm{kg})$. Total writhing movements were counted during a 30-min period starting $5 \mathrm{~min}$ after the acetic acid injection.

\section{Thermal plantar test}

To assess paw withdrawal latency (PWL) to a thermal nociceptive stimulus, the Hargreaves method [7] was utilized using intraperitoneal administrations of $0.9 \%$ saline (control group), vehicle, or EOE (45 and $90 \mathrm{mg} / \mathrm{kg}$ ) ( $\mathrm{n}=10$ per group). The plantar surface of the hind paw received the center of a focused beam of heat. To avoid tissue damage, the application of the beam was halted at $20 \mathrm{~s}$. With at least 1-min intervals, 4 measurements were obtained on each hind paw. The mean PWL of each group was evaluated using previously determined standard values for each hind paw.

\section{Rotarod test}

To measure whether the EOE could influence motor coordination, a rotarod test was applied. EOE (45, 90, and 180 $\mathrm{mg} / \mathrm{kg}$ ) and vehicle (almond oil) was administered intraperitoneally. Animals were subjected to spinning at 4 rpm ( $\mathrm{n}=10$ per group) using a rotating rod (Scitech Korea, Seoul, Korea). The rotation was progressively augmented at a rate of 1 revolutions per minute (rpm) after mouse stabilization. Infrared sensors recorded the time that the mice managed to remain on the rod and the speed at which they fell off. The average of three trials was used for each mouse.

\section{Statistical analysis}

Mean \pm standard error was used. One-way ANOVA, followed by Tukey's post hoc test was employed to evaluate differences among treatment groups. A $P$ value of $<0.05$ was considered statistically significant in all cases.

\section{RESULTS}

1. Effect of injection or inhalation of EOE on formalin test

After EOE intraperitoneal injections and pretreatment, the first ( $0-5 \mathrm{~min})$ and second (20-25 $\mathrm{min}$ ) phases of licking were recorded to investigate whether EOE has an antinociceptive or anti-inflammatory effect. Licking during the first phase was not reduced by EOE, whereas licking during the second phase was reduced by $91 \%$ (EOE $45 \mathrm{mg} / \mathrm{kg}: 4.1$ s vs, vehicle: $47.9 \mathrm{~s} ; P<0.001$ ) (Fig. 1). First phase inhibition using morphine as a positive control was reduced by $48 \%$ (morphine: 59.5 s vs. vehicle: $114.4 \mathrm{~s} ; P<0.01$ ) and by $80 \%$ during the second phase (morphine: $9.6 \mathrm{~s}$ vs. vehicle: $47.9 \mathrm{~s} ; P<0.001$ ). There were no substantial differences between the EOE group ( $45 \mathrm{mg} / \mathrm{kg}$ ) and the positive control group in the second phase.

The formalin test was used to determine whether inhalation of EOE has any effect on licking time (Fig. 2).

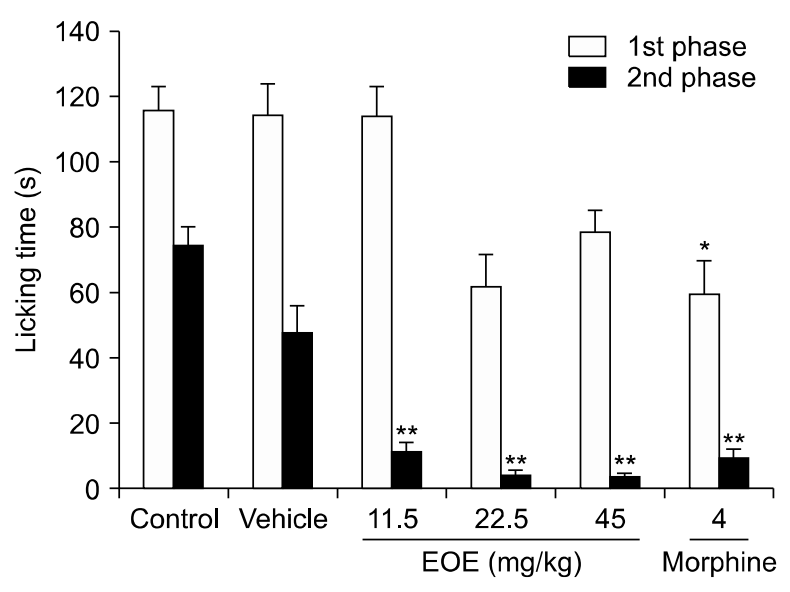

Fig. 1. Intraperitoneal (i.p.) injection of essential oil of Eucalyptus (EOE) reduced licking time in the second phase of the formalin test. Licking time in mice injected with control (0.9\% saline, i.p.), vehicle (almond oil, i.p.), essential oil $(11.25,22.5$, and $45 \mathrm{mg} / \mathrm{kg}$, i.p.), or morphine $(4 \mathrm{mg} / \mathrm{kg}$, i.p.) $30 \mathrm{~min}$ prior to the injection of $20 \mu \mathrm{l}$ of formalin ( $2 \%$ $\mathrm{v} / \mathrm{v}$ ) into the dorsal surface of their left, hind paws. Morphine, a positive control, reduced the licking time in the first phase (0-5 min). Meanwhile, EOE (45 mg/ $\mathrm{kg}$ ) and morphine significantly reduced licking time in the second phase (20-25 min). Each value represents the mean and standard error of mean. ${ }^{\star} P<0.05$, ${ }^{* \star} P<0.001$ compared to the vehicle group. One-way analysis of variance followed by Tuckey's post hoc test were performed for statistical analyses. The control group had 12 mice while the others had 8 mice. 


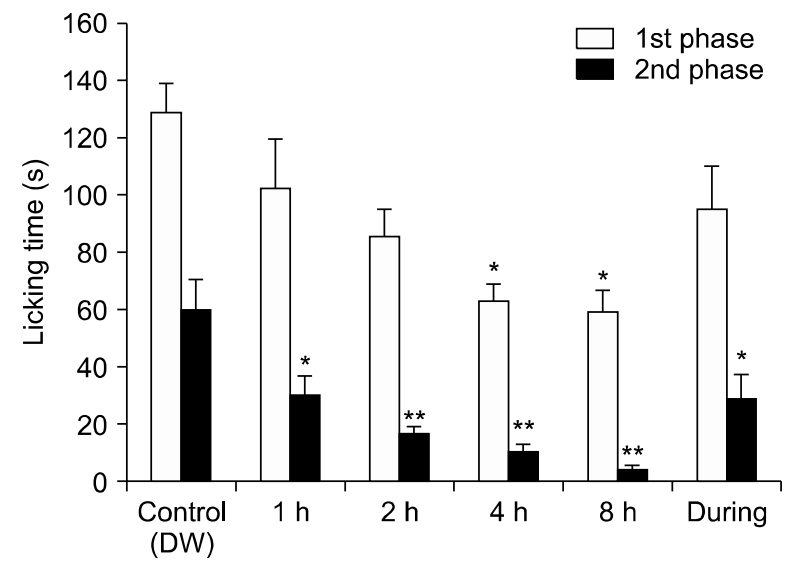

Fig. 2. The inhalation of essential oil of Eucalyptus (EOE) reduced licking time in the second phase of the formalin test. Licking time with the inhalation of control (distilled water $[D W]$ ) or $E O E$ mixed with the same volume of dextrose water for 1, 2, 4, 8, and during groups before the formalin test. Each value represents the mean and standard error of mean. ${ }^{\star} P<0.05$, ${ }^{\star \star} P<0.001$, compared to the control group. One-way analysis of variance followed by Tukey's post hoc test was used. The number of animals in the control group was 7 and in the during group was 8 .

Licking time was reduced by inhalation of EOE in the first phase; however, statistical significance was observed only after 4 and $8 \mathrm{~h}$ of inhalation $(P<0.01)$. A significantly shorter licking time began to appear within $1 \mathrm{~h}$ of inhalation and was observed at 1,2, 4, and $8 \mathrm{~h}$ compared to the control group in the second phase $(P<0.01,0.001$, 0.001 , and 0.001 , respectively). These data suggest that EOE exerted an antinociceptive effect on mice in the formalin test, especially when the results of injection and inhalation of EOE were considered together.

2. Association between the antinociceptive effect of EOE and opioid pathway on the formalin test

This experiment was designed to investigate the antinociceptive/analgesic effects of EOE on the opioid pathway (Fig. 3). EOE (45 mg/kg) and 5'-guanidinonaltrindole (0.3 $\mathrm{mg} / \mathrm{kg}$ ) or naltrindole $(5 \mathrm{mg} / \mathrm{kg}$ ) - which are $\mathrm{\kappa}$ - and $\delta$-opioid antagonists, respectively-were injected. Although there was no statistically significant difference when compared to that in the EOE only group, licking time was slightly increased in the second phase, compared to that in the EOE group. Naloxone decreased the licking time in the second phase in a dose dependent manner $(8 \mathrm{mg} / \mathrm{kg}, P<0.001$;

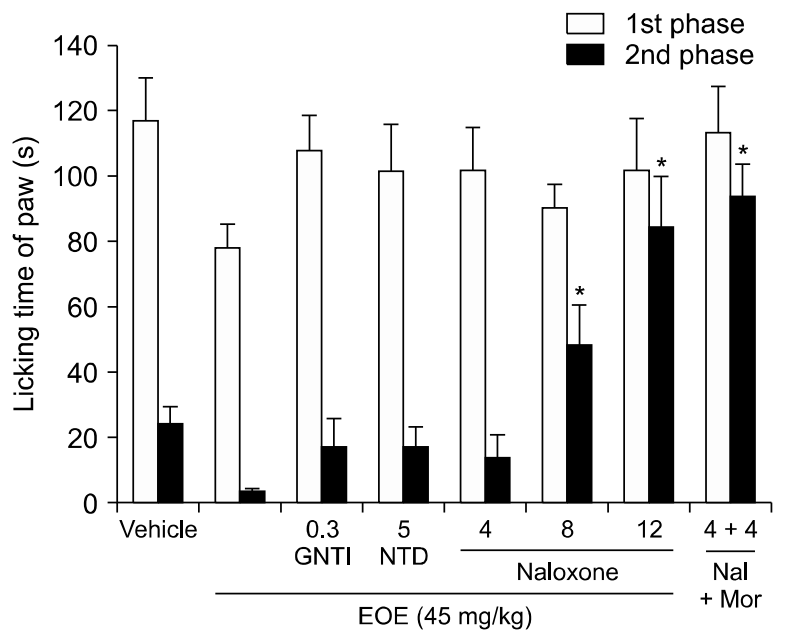

Fig. 3. The analgesic effects of essential oil of Eucalyptus (EOE) is via the $\mu$-opioid pathway as demonstrated by the formalin test. The relevance of antinociceptive effect of EOE via the opioid pathway was investigated in this experiment. The licking time after pretreatment with an antagonist of the opioid receptor 15 min before the injection of the EOE (45 mg/kg, intraperitoneal) is shown. 5'-guanidinonaltrindole (GNTI, א-opioid antagonist, $0.3 \mathrm{mg} / \mathrm{kg}$ ), naltrindole (NTD, $\delta$-opioid antagonist, $5 \mathrm{mg} / \mathrm{kg}$ ), and naloxone ( $\mathrm{Nal}, \mu$-opioid antagonist, 4, 8, $12 \mathrm{mg} / \mathrm{kg}$ ) plus EOE group were injected intraperitoneally. During the second phase, there was a noteworthy variance in licking time between the EOE group and the vehicle group. The naloxone group $(8,12 \mathrm{mg} / \mathrm{kg}$ ) and the naloxone plus EOE group showed statistically significant differences compared to the EOE treatment group in the second phase. Nal + Mor: naloxone $4 \mathrm{mg} / \mathrm{kg}+$ morphine $4 \mathrm{mg} / \mathrm{kg}$. Each value represents the mean and standard error of mean. ${ }^{\star} P<$ $0.05,{ }^{* \star} P<0.001$, compared to the EOE (45 mg/kg) only group. One-way analysis of variance followed by Tuckey's post hoc test were used to perform the statistical analyses. There were 8 mice in all groups, except there were 7 in the naloxone plus EOE group.

$12 \mathrm{mg} / \mathrm{kg}, P<0.001$, compared to EOE only group). Also, licking time significantly increased when naloxone and morphine were simultaneously injected. The antinociceptive effect of EOE acting through the $\mu$-opioid pathway in the formalin test was demonstrated in this experiment.

3. Antinociceptive effect of EOE on acetic acid-induced abdominal writhing test

Abdominal contraction is caused during the acetic acid-induced abdominal writhing test, which is a model to test 
visceral pain. Endogenous substances and other pain mediators (such as arachidonic acid via cyclooxygenase and prostaglandin biosynthesis) cause such pain. This visceral pain model varies from the formalin test, which is a model of somatic pain. To study whether EOE has an antinociceptive effect on visceral pain, this acetic acid-induced abdominal writhing test was utilized (Fig. 4). EOE reduced the number of writhing movements in a dose dependent manner. The number of writhing movements were inhibited by indomethacin and EOE (45 mg/kg) by $41.72 \%$ and $33.21 \%$, respectively (indomethacin: 9.63 , EOE $45 \mathrm{mg} / \mathrm{kg}$ : 12.1, vehicle: $29.0 ; P<0.001$, compared to the vehicle group).

\section{The effect of EOE in thermal plantar test}

The thermal plantar test (Fig. 5) was used to investigate the effect of EOE on nociceptive pain associated with ther-

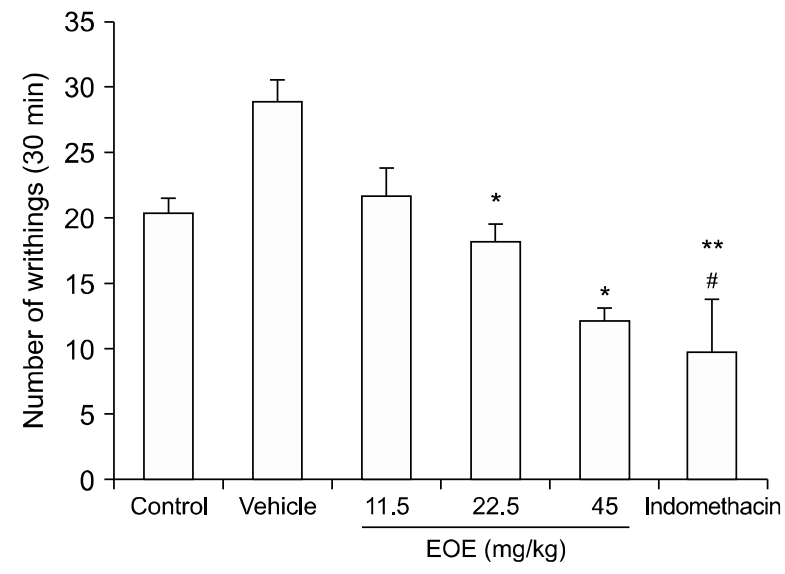

Fig. 4. Effect of essential oil of Eucalyptus (EOE) on writhing induced by acetic acid. Acetic acid-induced writhing test was used to determine whether EOE has an effect on visceral pain caused by an irritant injection. Control $(0.9 \%$ saline, i.p.), vehicle (almond oil, i.p.), essential oil (11.5, 22.5 , and $45 \mathrm{mg} / \mathrm{kg}$, i.p.), or indomethacin ( $10 \mathrm{mg} / \mathrm{kg}$, i.p.) were injected $30 \mathrm{~min}$ prior to administration of a $0.5 \%$ acetic acid solution $(10 \mathrm{ml} / \mathrm{kg})$. Five minutes after acetic acid injection, the total number of writhing movements were recorded for $30 \mathrm{~min}$. Writhing decreased from indomethacin and EOE $(22.5,45 \mathrm{mg} / \mathrm{kg})$. Each value represents the mean and standard error of mean. ${ }^{\star} P<0.05$, ${ }^{\star \star} P<<$ 0.001 compared to the vehicle group. ${ }^{\#} P<0.05$ compared to the control group. One-way analysis of variance followed by Tuckey's post hoc test was used. There were 10 mice in the control group and 8 in the other groups. i.p.: intraperitoneal. mal stimulus. Compared to values of the vehicle group, average withdrawal latencies of the EOE group presented no significant differences $(45,90$, and $180 \mathrm{mg} / \mathrm{kg})$. These data suggest that EOE administered at mild doses does not affect physiological pain associated with thermal stimuli.

5. Change of latency in mice treated with EOE in rotarod To examine the influence of EOE on motor coordination, a rotarod test was conducted (Fig. 6). No significant difference was observed with a $t$-test (compared to the vehicle group, $P=0.776)$, although the time EOE-treated mice $(45,90$, and $180 \mathrm{mg} / \mathrm{kg})$ managed to remain on the rod was slightly shorter than that of mice in the vehicle group. Despite the high concentration of EOE used, motor coordination was not affected, and there was no significant difference between the two groups.

\section{DISCUSSION}

In Brazilian folk medicine, various Eucalyptus species from

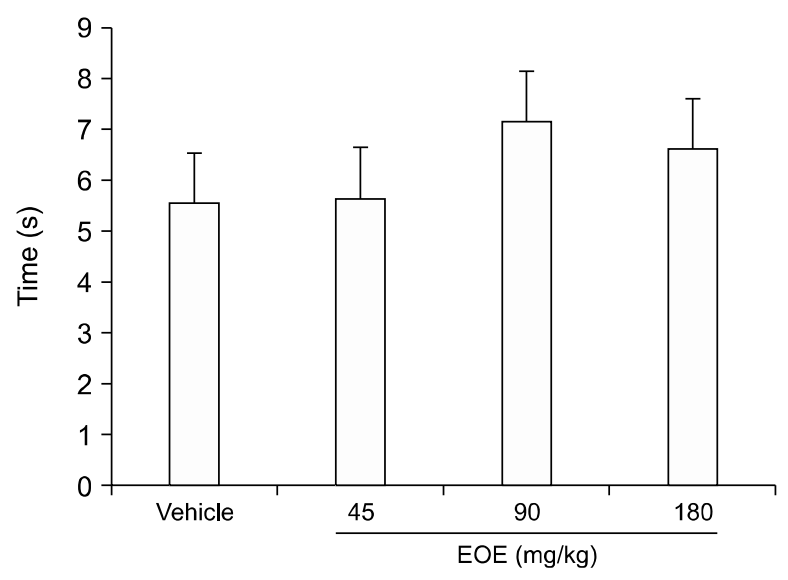

Fig. 5. Essential oil of Eucalyptus (EOE) does not have dose-dependent effects against thermal stimuli. To find out whether EOE alters physiological pain associated with thermal stimulus, the thermal plantar test was used. A pretreatment injection of $\operatorname{EOE}(45,90$, and $180 \mathrm{mg} / \mathrm{kg})$, or a vehicle were administered intraperitoneally. A focused beam of heat was aimed at the plantar surface of the hind paw in mice, 30 min after the pretreatment. Compared to the vehicle group, no remarkable difference in mean withdrawal latencies of the EOE groups (45, 90, and 180 $\mathrm{mg} / \mathrm{kg}$ ) was observed. Each value represents the mean and standard error of mean. One-way analysis of variance was used. There were 9 mice in each group. 


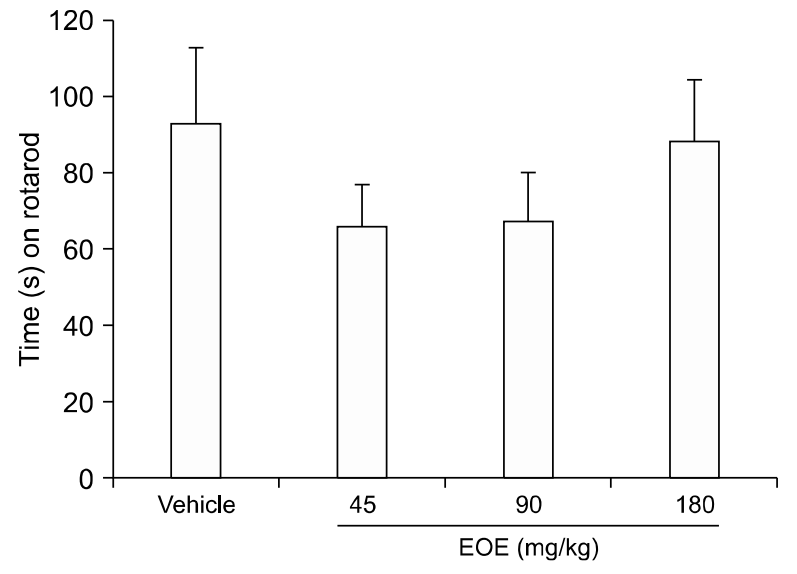

Fig. 6. Essential oil of Eucalyptus (EOE) did not affect motor coordination. A rotarod test was conducted to investigate whether the EOE could influence motor coordination. Vehicle (almond oil) or EOE $(45,90$, or $180 \mathrm{mg} / \mathrm{kg}$ ) were used for pretreatment. No significant differences were evident, although animals in the EOE group stayed on the rod for a shorter period than animals of the vehicle group. Each value represents the mean and standard error of mean. One-way analysis of variance was used. There were 10 mice in each group.

the Myrtaceae family are used to treat numerous medical conditions. Traditionally, for example, hot water extracts of the dried leaves of $E$. citriodora are used in cosmetics and for culinary purposes. Moreover, the extracts are also used to treat common cold, flu, and sinus congestion. However, as various essential oils have different active chemical components, they should be used appropriately according to their physiological effects. More interestingly, diverse analgesic effects have been shown among various species of Eucalyptus. Therefore, individual assessments of each species, assessing their analgesic effects, mechanism of action, and side effects are necessary for proper aromatherapy. Therefore, the purpose of this study was to elucidate the analgesic effects, pain pathways, and motor $\mathrm{co}^{-}$ ordination effects of EOE on somatic, visceral, thermal, and inflammatory nociception.

The formalin test was modified to evaluate inflammatory pain, nociceptive pain, and the central sensitization effects of EOE. Analgesic effects on inflammatory pain were observed through evaluation of the first and second phases after intraperitoneal injection or inhalation of EOE followed by hind-paw injection of $20 \mu \mathrm{L}$ of formalin ( $2 \%$ $\mathrm{v} / \mathrm{v})$. An analgesic effect of EOE was observed for nociceptive pain and for inflammatory pain. Moreover, com- pared to the analgesic effect of morphine (licking times: $9.6 \mathrm{~s}$ ), the analgesic effect of EOE was greater (licking times: 4.4 and $4.1 \mathrm{~s}$ for 22.5 and $45 \mathrm{mg} / \mathrm{kg}$, respectively). Although there was no analgesic effect in the first phase of the formalin test in conjunction with inhalation of EOE, dose-dependent (1, 2, 4, and $8 \mathrm{~h}$ ) analgesic effect was observed during the second phase. In other words, a higher analgesic effect was observed in the group that inhaled EOE $2 \mathrm{~h}$ prior to the formalin test than the group that inhaled EOE only during the formalin test. Therefore, the longer the inhalation of $\mathrm{EOE}$, the greater the analgesic effect. In conclusion, although EOE does not have an analgesic effect on somatic pain, there was an analgesic effect and central analgesic effect on inflammatory pain.

In our study, we first performed an intraperitoneal injection of EOE and then administered formalin $30 \mathrm{~min}$ later, referring to previous papers [8-11]. However, since EOE is a mixture of various ingredients, it is unclear when the maximum action will take place after intraperitoneal administration. However, the main component of EOE is 1,8-cineole which is lipophilic and passes easily through the cell membrane. Therefore, we think that the reason for not showing the effect in the first phase of the formalin test is that there may be no drug effect. Essential oils, composed of many different molecules, enter the olfactory bulb via the nose where they can exert effects on the olfactory cortex, which is connected to various regions of the brain. Many studies on pain have shown that the limbic system is connected to the amygdala and hippocampus [11-13], which control emotion and memories.

After injecting $\mathrm{EOE}(11.5,22.5$, or $45 \mathrm{mg} / \mathrm{kg}$ each) and indomethacin $(10 \mathrm{mg}$ ) intraperitoneally, an anti-nociceptive effect was observed during the writhing test. A statistically significant analgesic effect at $45 \mathrm{mg} / \mathrm{kg}$ of EOE was observed compared to that of the control group (12.1 vs. 20.3 writhing movements/30 min), and a similar effect was observed for the indomethacin group (9.63 writhing movements/30 min). Visceral pain involves different pain expression pathways from those of somatic pain. Sensory innervation of the viscera not only includes bilateral spinal, thoracic, and most abdominal organs, but also includes vagal afferents. Spinal afferents conduct noxious stimuli and vagus afferents conduct chemonociception, autonomic, and emotion responses [14,15]. Such stimulation to the viscera is amplified and modulated by passing through voltagegated and ligand-gated ion channels of the spinal cord and 
supraspinal area. Through these processes, the message is diffused and poorly localized, and is specifically shown as referred patterns. Moreover, in central levels, the analgesic mechanism is shown in relation to typical emotional and autonomic responses [16]. Therefore, visceral pain is a complex pathway in which the receptive ending, ion channel, chemical substance, nerve transmission, and modulation are related. In this study, we can expect that, although EOE did not have analgesic effects on somatic and thermal nociception, the analgesic effect observed against visceral pain may involve interactions in diverse parts the body. Similarly, intraperitoneal injection (5 and $10 \mathrm{mg} / \mathrm{kg}$ ) of essential oils of $C$. citratus followed by the acetic acid-induced writhing test showed inhibition (48 and 87\%) [17].

A plantar test was used to detect the thermal anti-nociceptive effect of intraperitoneally injected EOE. Although the concentrations of injected EOE (45, 90, and $180 \mathrm{mg} / \mathrm{kg}$ each) were increased, there was no statistically significant result, suggesting that EOE does not affect normal thermal sensation.

A well-known analgesic effect of EOE is that it acts as a potent inhibitor of the inflammatory response through the arachidonic acid metabolic pathway by inhibiting the production of leukotriene B2, prostaglandin E2, and other arachidonic acid metabolites such as eucalyptol [4]. In this experiment, 5'-guanidinonaltrindole ( $\mathrm{\kappa}$-opioid antagonist, $0.3 \mathrm{mg} / \mathrm{kg}$ ) and naltrindole ( $\delta$-opioid antagonist, $5 \mathrm{mg} / \mathrm{kg}$ ) could not antagonize Eucalyptus, but naloxone (non-selective opioid antagonist, 4, 8, $12 \mathrm{mg} / \mathrm{kg}$ ) could. Naloxone is a non-selective opioid antagonist and its binding affinity is highest for the $\mu$-opioid receptor, then the $\delta$-opioid receptor, and lowest for the $\kappa$-opioid receptor. In the present study, the analgesic effects of Eucalyptus was not antagonized by the $\kappa$-opioid antagonist and $\delta$-opioid antagonist. However, the analgesic effects of Eucalyptus was antagonized by naloxone, a non-selective opioid antagonist. Therefore, the $\mu$-opioid receptors are involved in the analgesic effects of EOE.

However, naloxone failed to modify the response of 1,8-cineole (cineole), suggesting a non-participation of $\mu$-opioid receptors in the effects of cineole which is a principal component of EOE [18]. Liapi et al. [18] used the tail-flick and hot-plate tests, reflecting the spinal and supra-spinal levels, respectively. We used the formalin test, in which the response to formalin shows an early and a late phase. The early phase seems to be caused predominantly by $\mathrm{C}$-fiber activation due to the peripheral stimulus, while the late phase appears to be dependent on the combination of an inflammatory reaction in the peripheral tissue and functional changes in the dorsal horn of the spinal cord. In the present study, naloxone could antagonize the analgesic effects of EOE in a dose dependent manner. It is therefore likely that $\mu$-opioid receptors at the periphery are involved in the effect of EOE, unlike the findings of Liapi et al. [18]. Further studies are needed on the deferent mechanism by which EOE acts in the central and peripheral regions.

The rotarod test evaluates the effect of a drug on motor the coordination of animals and is helpful to determine drug safety in humans. There was no statistically significant difference in the results between the treatment and control groups even when a high concentration of EOE (180 mg/kg) was utilized. This shows the possibility of EOE being developed as a new class of medicine, as it does not affect motor coordination.

In conclusion, the present study elucidated the anti-inflammatory effects of EOE. Furthermore, its inherent medical specifications were reported in relation to species. This study also demonstrated the analgesic effects of EOE on nociception and inflammation, and that the anti-inflammatory effect of EOE likely affects the $\mu$-opioid pathway. Moreover, EOE did not affect motor coordination. Thus, the combined results suggest that EOE has the potential to be developed into an analgesic agent to treat various types of pain. Further studies are necessary to improve our understanding of the pharmacology of EOE, and to elucidate the mechanism of action of these effects in other pain tests in addition to the formalin test using EOE's isolated active components and purified ingredients for the treatment of pain.

\section{ACKNOWLEDGEMENTS}

This research was supported by the Bio \& Medical Technology Development Program of the National Research Foundtion (NRF) \& funded by the Korean government (MSIP \& MOHW; No. 2016M3A9B6904244) and NRF (2015R1D1A1 A01061326) 


\section{CONFLICT OF INTEREST}

No potential conflict of interest relevant to this article was reported.

\section{REFERENCES}

1. Marchand S, Goffaux P. Pain processing in the cingulate cortex, behavioral studies in humans. In: Encyclopedia of pain. Edited by Schmidt RF, Willis WD. Berlin, Heidelberg, Springer. 2007, pp 1732-4.

2. Cockcroft A, Cosgrove JB, Wood RJ. Comparative repellency of commercial formulations of deet, permethrin and citronellal against the mosquito Aedes aegypti, using a collagen membrane technique compared with human arm tests. Med Vet Entomol 1998; 12: 289-94.

3. Juergens UR, Stöber $M$, Schmidt-Schilling $L$, Kleuver $T$, Vetter $\mathrm{H}$. Antiinflammatory effects of euclyptol (1.8-cineole) in bronchial asthma: inhibition of arachidonic acid metabolism in human blood monocytes ex vivo. Eur J Med Res 1998; 3: 407-12.

4. Trigg JK. Evaluation of a eucalyptus-based repellent against Anopheles spp. in Tanzania. J Am Mosq Control Assoc 1996; 12: 243-6.

5. Hunskaar S, Hole K. The formalin test in mice: dissociation between inflammatory and non-inflammatory pain. Pain 1987; 30: 103-14

6. Quintans-Júnior L, Moreira JC, Pasquali MA, Rabie SM, Pires AS, Schröder R, et al. Antinociceptive activity and redox profile of the monoterpenes $(+)$-camphene, $p$-cymene, and geranyl acetate in experimental models. ISRN Toxicol 2013; 2013: 459530

7. Hargreaves K, Dubner R, Brown F, Flores C, Joris J. A new and sensitive method for measuring thermal nociception in cutaneous hyperalgesia. Pain 1988; 32: 77-88.

8. Silva J, Abebe W, Sousa SM, Duarte VG, Machado MI, Matos FJ. Analgesic and anti-inflammatory effects of essential oils of Eucalyptus. J Ethnopharmacol 2003; 89: 277-83.

9. Daniel AN, Sartoretto SM, Schmidt G, Capparoz-Assef SM, Bersani-Amado CA, Cuman RK. Anti-inflammatory and antinociceptive activities A of eugenol essential oil in experimental animal models. Rev Bras Farmacogn 2009; 19: 212-7.

10. Abdollahi M, Karimpour H, Monsef-Esfehani HR. Antinociceptive effects of Teucrium polium $L$ total extract and essential oil in mouse writhing test. Pharmacol Res 2003; 48: $31-5$.

11. Bannerman DM, Rawlins JN, McHugh SB, Deacon RM, Yee BK. Bast T, et al. Regional dissociations within the hippocampus: memory and anxiety. Neurosci Biobehav Rev 2004; 28: 273-83.

12. Hobin JA, Ji J, Maren S. Ventral hippocampal muscimol disrupts context-specific fear memory retrieval after extinction in rats. Hippocampus 2006; 16: 174-82.

13. Trivedi MA, Coover GD. Lesions of the ventral hippocampus, but not the dorsal hippocampus, impair conditioned fear expression and inhibitory avoidance on the elevated T-maze. Neurobiol Learn Mem 2004; 81: 172-84.

14. Ness TJ, Gebhart GF. Visceral pain: a review of experimental studies. Pain 1990; 41: 167-234.

15. Cervero F. Sensory innervation of the viscera: peripheral basis of visceral pain. Physiol Rev 1994; 74: 95-138.

16. Ferreira $\mathrm{SH}$. A classification of peripheral analgesics based upon their mode of action. In: Migraine: a spectrum of ideas. Edited by Sandler M, Collins GM. Oxford, Oxford University Press. 1990, pp 59-72.

17. Viana GS, Vale TG, Pinho RS, Matos FJ. Antinociceptive effect of the essential oil from Cymbopogon citratus in mice. J Ethnopharmacol 2000; 70: 323-7.

18. Liapi C, Anifandis G, Chinou I, Kourounakis AP, Theodosopoulos S, Galanopoulou P. Antinociceptive properties of 1,8-Cineole and beta-pinene, from the essential oil of Eucalyptus camaldulensis leaves, in rodents. Planta Med 2007; 73: 1247-54 